\title{
Work characteristics and psychiatric disorder in civil servants in London
}

\author{
S A Stansfeld, F M North, I White, M G Marmot
}

\begin{abstract}
Study objective - To describe the association between self reported and externally assessed work characteristics and psychiatric disorder.

Design - Analysis of questionnaire data collected from the first phase of the Whitehall II study, a cohort study of an employed population.
\end{abstract}

Setting - Twenty civil service departments in London.

Participants - Altogether 6900 male and 3414 female civil servants aged 35-55 years. Main results - High levels of subjective social support at work, control at work, job variety, and skill use were associated with greater satisfaction and wellbeing and less psychiatric disorder measured by the 30 item general health questionnaire (GHQ). High levels of subjective work pace and conflicting demands were associated with less satisfaction and wellbeing and greater psychiatric disorder. The combined effects of work characteristics were similar to the effects of the work characteristics considered separately, except that for men there was a small interaction between psychological demands and control on the GHQ. There was little overall support for the two factor job strain model. In contrast, objective indices of work were generally not associated with the psychological indices. Findings in men and women were generally comparable and were not significantly influenced by employment grade.

Academic Department of Psychiatry,

University College

London Medical

School, Wolfson

Building, Riding

House Street, London

W1N 8AA

S A Stansfeld

Department of Preventive and Social Medicine, Medical School, University of Otago, Dunedin, New Zealand

F M North

Department of Epidemiology and Public Health University College, London

M G Marmot

Correspondence to: Dr S Stansfeld.

Accepted for publication June 1994 Conclusions - Negative affectivity and a tendency to report negatively about both partly explain the difference in the findings between subjective and objective work characteristics. However, subjective work characteristics were still associated with psychiatric disorder after adjusting for negative affectivity. The potential confounding effects of employment grade did not explain the association between either subjective or objective work characteristics and the psychological indices. While modifications to the work environment may directly reduce certain adverse physical health effects, the influence of work place design and management on psychological wellbeing, satisfaction, and psychiatric disorder may be mediated through subjective perceptions of the work environment.

(f Epidemiol Community Health 1995;49:48-53)
Many studies have examined the relationship between work characteristics and psychological health outcomes. ${ }^{1-6}$ Psychological health outcomes have been broadly defined to include satisfaction, psychosomatic complaints, self confidence, happiness, and vulnerability as well as psychiatric disorder. As Payne and Fletcher ${ }^{4}$ have pointed out, this diversity of psychological outcomes is confusing. Moreover, different work characteristics seem to be associated with specific affective outcomes. For example, job demands seem to relate to anxiety but not depression, while work control seems to relate to depression rather than anxiety. ${ }^{7-9}$

In previous studies several different models of work characteristics have been used. ${ }^{211}$. This study is based on the "job strain model" proposed by Karasek ${ }^{2}$ which has been tested in relation to a wide range of outcomes. This is comprised of two major dimensions, decision latitude and psychological work load. Decision latitude is made up of skill discretion, the breadth of skills a worker can use on a job, and decision authority, the amount of authority the worker has over decision making. Together these measure the degree of control the worker has over their job. This model suggests that the combined, rather than separate, effects of job demands and control or variety and skill use are important. For example, high demands combined with low control result in higher levels of job strain than high demands combined with high control. Subsequently, the model has been expanded to suggest that social support at work also influences levels of job strain. ${ }^{112}$

Associations have been found between job work and the psychological indices may demands and control and psychological outcomes. ${ }^{2}$ However, many of the studies have been criticised for relying on subjective self report measures of work and psychological indices. The associations may be partly explained by common method variance, ${ }^{13}$ job attitudes, ${ }^{14}$ negative affectivity leading to negative reports of both work and mood ${ }^{15}$ or reverse causation ${ }^{16}$ - poor health leads to a deterioration in perceived or actual working conditions. Few studies have observed whether these associations are affected by social class or are similar in men and women doing the same jobs. This paper reports how work characteristics are associated with psychological outcomes in male and female civil servants from the cross sectional phase of the Whitehall II study. It compares self report and external assessments of the work environment in relation to the psychological indices, examines the potential confounding effect of employment grade, and assesses whether negative affectivity can explain 
the association between subjective measures of work and health.

\section{Methods}

All male and female civil servants, aged between 35 and 55 years, in 20 London based civil service departments were sent an introductory letter and screening questionnaire and were offered a screening examination for cardiovascular disease. Full details of the screening procedure are reported elsewhere. ${ }^{18}$ Altogether 10314 civil servants were examined - 6900 men and 3414 women. The response rate, after excluding those who were ineligible, was $73 \%$ ( $74 \%$ in men, $71 \%$ in women). The true response rates are likely to be higher, however, because $4 \%$ of those on the list of employees had moved before the study and were therefore not eligible for inclusion.

\section{SCREENING QUESTIONNAIRE}

The questionnaire included questions on diet, alcohol consumption, smoking habits, physical exercise, work characteristics, social support, life events, chronic difficulties, physical health, psychological wellbeing, satisfaction, and psychiatric disorder.

\section{PSYCHIATRIC DISORDER}

The major measure of psychiatric disorder was the 30 item general health questionnaire ${ }^{18}$ (GHQ) which was validated against the clinical interview schedule ${ }^{19}$ (CIS) in a subsample. A threshold of $4 / 5$ on the GHQ was chosen on the basis of receiver operating characteristic analysis. ${ }^{20}$ At this threshold the sensitivity of the GHQ was $72 \cdot 7 \%$ and the specificity was $78.0 \%$ against the CIS. ${ }^{21}$ The GHQ is a well established screening questionnaire for minor psychiatric disorder suitable for use in general and clinic population samples. All those scoring $0-4$ on the GHQ, scored in the conventional manner, were considered "non-cases" and those scoring 5 + were deemed "GHQ cases". To measure the effects of work characteristics on depression and anxiety we selected four items for depression and five items for anxiety from the GHQ. We selected items from the 30 item questionnaire which were also present in the depression and anxiety subscales respectively of the scaled 28 item GHQ. These were scored by summing all items scored on a Likert scale from 0 to 3 for each subscale. Wellbeing was measured by the affect balance scale, a 10 item scale measuring the affect balance score comprised of the negative affect (five items) subtracted from positive affect (five items). ${ }^{22}$ Global satisfaction was measured by the five item satisfaction with life scale. ${ }^{23}$

\section{WORK CHARACTERISTICS}

Self report

Initially, there were 67 self report questions on work characteristics based on the job strain model and also including work social support, job satisfaction, and coping skills related to work problems answered on a four point scale from "often" to "never/almost never". Using principal components analysis, seven dimensions of work characteristics were derived. ${ }^{23}$ Questions on work pace included, "Do you have to work very fast? Do you have to work very intensively? Do you have enough time to do everything?" Questions on conflicting demands included, "Do different groups at work demand things from you that you think are hard to combine? Is your job too varied and split up?" Control over work included, "Do you have a choice in deciding how you do your work? Do you have a choice in deciding what you do at work? Others take decisions about my work. I have a good deal of say in decisions about my work. My working time can be flexible. I can decide when to take a break. I have a say in choosing with whom I work. I have a great deal of say in planning my work environment". Pace and conflicting demands are similar to Karasek's psychological demands, and skill use and variety and control are similar to decision latitude. The additional dimensions were work social support, job importance, and job satisfaction. Each work index was calculated by adding responses to the questions described above and the score for each work index was classified using tertiles into high, medium, and low levels.

\section{External assessments}

The work characteristics were measured by personnel managers' assessment of the jobs in terms of control, work pace, and conflicting demands in 18 of the 20 civil service departments. ${ }^{24}$ Objective work characteristics were obtained for 8838 respondents.

The score for each work index was classified using tertiles into high, medium, and low levels.

\section{STATISTICAL METHODS}

Psychological health outcomes were taken as the dependent variable in multiple linear regression models ( $S A S, G L M$ procedure); work characteristics (grouped into tertiles), five year age group, employment grade, and (where appropriate) marital status were independent categorical variables. Results are presented as least-square means for each level of the work characteristic (giving estimates of the mean psychological health outcome adjusted for age and employment grade). Psychiatric disorder was taken as the dependent variable in a multiple logistic regression model ( $S A S, C A T M O D$ procedure) with the same independent variables. Results are presented as the odds of psychiatric disorder in a particular tertile of work characteristic compared with all tertiles combined.

\section{Results}

There was a consistent picture for the positive aspects of work; increasing levels of skill and variety, control, and job support were related to less psychiatric disorder, greater wellbeing, and greater global satisfaction in both men and women (table 1). As work characteristics are associated with employment grade, these res- 
Table 1 Psychiatric disorder, wellbeing, and global satisfaction by work characteristics adjusting for age and employment grade

\begin{tabular}{|c|c|c|c|}
\hline \multirow[b]{2}{*}{ Work characteristics } & \multicolumn{3}{|l|}{ Scores } \\
\hline & 1 (low) & 2 (middle) & 3 (high) \\
\hline \multicolumn{4}{|l|}{ Skill and variety } \\
\hline \multicolumn{4}{|l|}{ Men } \\
\hline $\begin{array}{l}\text { GHQ } \\
\text { ABS }\end{array}$ & $\begin{array}{l}4.09(0.13) \\
1.74(0.11)\end{array}$ & $\begin{array}{l}3.29(0 \cdot 11) \\
3.38(0.10)\end{array}$ & $2 \cdot 80(0.11)^{*}$ \\
\hline SWLS & $13.46(0.19)$ & $15 \cdot 65(0 \cdot 17)$ & $16.9(0.17)^{*}$ \\
\hline \multicolumn{4}{|l|}{ Women } \\
\hline GHQ & $5 \cdot 27(0 \cdot 21)$ & $4 \cdot 34(0 \cdot 22)$ & $3.91(0.23)^{*}$ \\
\hline ABS & $1.75(0.21)$ & $3.32(0.21)$ & $4.79(0.23)$ \\
\hline SWLS & $13.88(0.33)$ & $16 \cdot 04(0 \cdot 34)$ & $17 \cdot 36(0 \cdot 36)^{*}$ \\
\hline \multicolumn{4}{|l|}{ Control } \\
\hline \multicolumn{4}{|l|}{ Men } \\
\hline GHQ & $4 \cdot 28(0 \cdot 13)$ & $3.36(0.11)$ & $2.70(0.11)^{*}$ \\
\hline ABS & $2 \cdot 19(0 \cdot 12)$ & $3.51(0 \cdot 10)$ & $4.34(0 \cdot 10)^{*}$ \\
\hline SWLS & $14 \cdot 11(0 \cdot 20)$ & $15 \cdot 25(0.17)$ & $16.54(0 \cdot 16)^{*}$ \\
\hline \multicolumn{4}{|l|}{ Women } \\
\hline GHQ & $5.33(0.21)$ & $4 \cdot 32(0 \cdot 20)$ & $3.94(0.22)^{*}$ \\
\hline ABS & $2 \cdot 16(0 \cdot 20)$ & $3.42(0.20)$ & $4.27(0.22)^{*}$ \\
\hline SWLS & $14 \cdot 15(0 \cdot 32)$ & $15 \cdot 17(0 \cdot 32)$ & $17.51(0.34)^{*}$ \\
\hline \multicolumn{4}{|l|}{ Work social support } \\
\hline \multicolumn{4}{|l|}{ Men } \\
\hline GHQ & $4.45(0 \cdot 11)$ & $3 \cdot 30(0 \cdot 11)$ & $2.43(0.11)^{*}$ \\
\hline ABS & $2.37(0 \cdot 10)$ & $3.61(0 \cdot 10)$ & $4.46(0 \cdot 10)^{*}$ \\
\hline SWLS & $14 \cdot 27(0 \cdot 17)$ & $15 \cdot 46(0 \cdot 17)$ & $16.63(0.17)^{*}$ \\
\hline \multicolumn{4}{|l|}{ Women } \\
\hline GHQ & $5 \cdot 51(0 \cdot 19)$ & $4 \cdot 21(0 \cdot 21)$ & $3.61(0.20)^{*}$ \\
\hline ABS & $2.25(0.19)$ & $3.62(0.20)$ & $4.31(0.20)^{*}$ \\
\hline SWLS & $14 \cdot 78(0 \cdot 30)$ & $15.93(0.32)$ & $16.91(0.32)^{*}$ \\
\hline \multicolumn{4}{|l|}{ Work pace } \\
\hline \multicolumn{4}{|l|}{ Men } \\
\hline GHQ & $2 \cdot 81(0 \cdot 12)$ & $3.06(0 \cdot 11)$ & $4.23(0 \cdot 11)^{*}$ \\
\hline ABS & $3.35(0.11)$ & $3.50(0.10)$ & $3.49(0 \cdot 10)$ \\
\hline SWLS & $16 \cdot 0 \quad(0 \cdot 18)$ & $15 \cdot 42(0 \cdot 17)$ & $14.86(0 \cdot 18)^{*}$ \\
\hline \multicolumn{4}{|l|}{ Women } \\
\hline GHQ & $3 \cdot 71(0 \cdot 22)$ & $4 \cdot 16(0 \cdot 20)$ & $5.30(0.20)^{*}$ \\
\hline ABS & $3.48(0.21)$ & $3.31(0 \cdot 19)$ & $3.23(0.20)$ \\
\hline SWLS & $16.50(0.33)$ & $15 \cdot 7(0.31)$ & $15.4(0.32)^{*}$ \\
\hline \multicolumn{4}{|l|}{ Conflicting demands } \\
\hline GHQ & $2 \cdot 27(0 \cdot 14)$ & $3.11(0.09)$ & $4.54(0.11)^{*}$ \\
\hline ABS & $4 \cdot 17(0 \cdot 12)$ & $3.53(0.08)$ & $2 \cdot 82(0 \cdot 10)^{*}$ \\
\hline SWLS & $16.52(0.21)$ & $15.57(0.14)$ & $14.37(0 \cdot 18)^{*}$ \\
\hline \multicolumn{4}{|l|}{ Women } \\
\hline GHQ & $3.42(0.21)$ & $4 \cdot 21(0 \cdot 19)$ & $5.86(0.23)^{*}$ \\
\hline ABS & $3.73(0.10)$ & $3.52(0.18)$ & $2.60(0.23)^{*}$ \\
\hline SWLS & $16 \cdot 28(0.32)$ & $16.08(0.29)$ & $14.88(0.36)^{*}$ \\
\hline
\end{tabular}

p<0.0001. $\mathrm{GHQ}=\mathrm{scores}$ on the general health questionnaire - a high score indicates more negative
symptoms; $\mathrm{ABS}=$ affect balance scale - a high score indicates more positive than negative affect; symptoms; $A B S=$ affect balance scale - a high score indicates more positive th
SWL $S=$ satisfaction with life scale - a high score indicates higher satisfaction.

Table 2 Psychiatric disorder, wellbeing, and global satisfaction by externally assessed work characteristics adjusting for age and employment grade (6 levels)

\begin{tabular}{|c|c|c|c|}
\hline \multirow[b]{2}{*}{ Work characteristics } & \multicolumn{3}{|l|}{ Scores } \\
\hline & 1 (low) & 2 (middle) & 3 (high) \\
\hline \multicolumn{4}{|l|}{$\begin{array}{l}\text { Control } \\
\text { Men }\end{array}$} \\
\hline $\begin{array}{l}\text { GHQ } \\
\text { ABS } \\
\text { SWLS }\end{array}$ & $\begin{array}{r}3.61(0.15) \\
3.07(0.13) \\
15.04(0.22)\end{array}$ & $\begin{array}{r}3.36(0.12) \\
3.54(0.10) \\
15.51(0.17)\end{array}$ & $\begin{array}{c}3.21(0.13)^{* * *} \\
3.59(0.11) \\
15.72(0.19)\end{array}$ \\
\hline \multicolumn{4}{|l|}{ Women } \\
\hline $\begin{array}{l}\text { GHQ } \\
\text { ABS } \\
\text { SWLS }\end{array}$ & $\begin{array}{r}4.27(0.23) \\
3.27(0.22) \\
15.75(0.35)\end{array}$ & $\begin{array}{r}4.49(0.21) \\
3.13(0.21) \\
15 \cdot 18(0.32)\end{array}$ & $\begin{array}{c}4.39(0.25) \\
3.53(0.24) \\
16.30(0.38)^{*}\end{array}$ \\
\hline \multicolumn{4}{|l|}{ Work pace } \\
\hline \multicolumn{4}{|l|}{ Men } \\
\hline $\begin{array}{l}\text { GHQ } \\
\text { ABS } \\
\text { SWLS }\end{array}$ & $\begin{array}{r}4.09(0.13) \\
3.26(0.11) \\
15.38(0.23)\end{array}$ & $\begin{array}{r}3.22(0.11) \\
3.39(0.10) \\
15.33(0.17)\end{array}$ & $\begin{array}{l}3.48(0.13) \\
3.64(0.12)^{* *} \\
15.65(0.20)\end{array}$ \\
\hline \multicolumn{4}{|l|}{ Women } \\
\hline $\begin{array}{l}\text { GHQ } \\
\text { ABS } \\
\text { SWLS }\end{array}$ & $\begin{array}{r}4.09(0.23) \\
3.30(0.22) \\
16.32(0.34)\end{array}$ & $\begin{array}{r}4.57(0.20) \\
3.18(0.20) \\
15.49(0.31)\end{array}$ & $\begin{array}{c}4.43(0.23) \\
3.42(0.22) \\
15.38(0.35)^{*}\end{array}$ \\
\hline \multicolumn{4}{|l|}{$\begin{array}{l}\text { Conflicting demands } \\
\text { Men }\end{array}$} \\
\hline $\begin{array}{l}\text { GHQ } \\
\text { ABS } \\
\text { SWLS }\end{array}$ & $\begin{array}{r}3.30(0.13) \\
3.28(0.11) \\
15.43(0.18)\end{array}$ & $\begin{array}{r}3.36(0.13) \\
3.41(0.11) \\
15.34(0.19)\end{array}$ & $\begin{array}{r}3.48(0.19) \\
3.56(0 \cdot 10) \\
15.51(0.18)\end{array}$ \\
\hline Women & & & \\
\hline $\begin{array}{l}\text { GHQ } \\
\text { ABS } \\
\text { SWLS }\end{array}$ & $\begin{array}{r}4.17(0.23) \\
2.91(0.21) \\
15 \cdot 71(0.34)\end{array}$ & $\begin{array}{r}4.48(0.23) \\
3.51(0.22) \\
15.82(0.35)\end{array}$ & $\begin{array}{c}4.50(0.21) \\
3.43(0.21)^{*} \\
15.55(0.33)\end{array}$ \\
\hline
\end{tabular}

ults have been adjusted for the effects of employment grade.

Mean GHQ scores, measuring degree of psychiatric disorder, rose with increasing levels (measured in tertiles) of work pace and conflicting demands in both men and women (table 1). The picture with global satisfaction was similar; it decreased with both increasing work pace and conflicting demands. However, although wellbeing on the affect balance scale fell with increasing conflicting demands there was little association with work pace.

By contrast, the external assessments of work characteristics measured by personnel managers' perception of jobs were not associated with psychological health outcomes except that greater control over work was significantly associated with lower GHQ scores in men and higher global satisfaction scores in women (table 2).

Odds ratios for psychiatric disorder, measured by the GHQ, for self reports and external assessments of work, adjusting for age and employment grade, are reported in table 3. There was very little change in these results after adjusting for employment grade in addition to age.

Using strictly defined Karasek work indices, there was an interaction between psychological demands (work pace + conflicting demands) and decision latitude (control + variety and skill use) for men in relation to GHQ scores, adjusting for age and employment grade, which was statistically significant at the level $p<0 \cdot 05$. The same pattern was seen for women, although it was not statistically significant. In men, $36.5 \%$ of those in the "high strain" cell were possible cases of psychiatric disorder (mean GHQ score $=5.83$ ) compared with $15.7 \%$ in the "low strain" cell (mean GHQ score $=3 \cdot 01$ ). For men with low demands and low decision latitude the mean GHQ score was 3.98; for men with high demands and high decision latitude the mean GHQ score was 4.35 . In women, $40.8 \%$ of those in the high strain cell were possible cases of psychiatric disorder (mean GHQ score $=6 \cdot 56$ ) compared with $20.3 \%$ in the low strain cell (mean GHQ score $=3 \cdot 28$ ). For women with low demands and low decision latitude the mean GHQ score was 4.65; for women with high demands and high decision latitude the mean GHQ score was 4.71. The interaction between psychological demands and decision latitude was not statistically significant for wellbeing or global satisfaction.

In agreement with published reports, ${ }^{7-9}$ work pace had a stronger association with anxiety than depression in both men and women (table 4). However, control was linked with both depression and anxiety. Moreover, conflicting demands as an aspect of psychological work demands were strongly associated with both depression and anxiety, although most powerfully with anxiety (table 4 ).

To assess the relative importance of each of these work characteristics in relation to psychological disorder, linear models were analysed, in which GHQ scores were the dependent variable, and each of the work char- 
Table 3 Odds ratios for psychiatric disorder by subjective and objective work indices adjusting for age and employment grade

\begin{tabular}{|c|c|c|c|c|c|c|}
\hline \multirow[b]{2}{*}{ Work indices } & \multirow[b]{2}{*}{ Sex } & \multirow[b]{2}{*}{ Count } & \multicolumn{3}{|c|}{ Work index } & \multirow{2}{*}{$\begin{array}{l}\text { p value, } \\
\text { intertertile } \\
\text { trend }\end{array}$} \\
\hline & & & Low & Medium & High & \\
\hline \multicolumn{7}{|l|}{ Subjective: } \\
\hline Skill and variety & $\begin{array}{l}\mathrm{M} \\
\mathrm{F}\end{array}$ & $\begin{array}{l}6821 \\
3306\end{array}$ & $\begin{array}{l}1.29 \\
1.26\end{array}$ & $\begin{array}{l}0.96 \\
0.92\end{array}$ & $\begin{array}{l}0 \cdot 81 \\
0.86\end{array}$ & $\begin{array}{l}0.0001 \\
0.0006\end{array}$ \\
\hline \multirow{2}{*}{ Control } & $\mathbf{M}$ & 6826 & $1 \cdot 31$ & 0.99 & 0.77 & 0.0001 \\
\hline & $\mathrm{F}$ & 3294 & $1 \cdot 26$ & $1 \cdot 02$ & 0.78 & 0.0001 \\
\hline \multirow[t]{2}{*}{ Work social support } & $\mathbf{M}$ & 6823 & 1.53 & 1.01 & 0.64 & 0.0001 \\
\hline & $\mathbf{F}$ & 3303 & 1.39 & 0.94 & 0.77 & 0.0001 \\
\hline \multirow[t]{2}{*}{ Job importance } & $\mathbf{M}$ & 6822 & 1.26 & 0.99 & $0 \cdot 80$ & 0.0001 \\
\hline & $\mathbf{F}$ & 3307 & $1 \cdot 15$ & 0.93 & 0.93 & 0.0355 \\
\hline \multirow[t]{2}{*}{ Job satisfaction } & $\mathbf{M}$ & 6818 & $1 \cdot 79$ & 0.91 & $0 \cdot 61$ & 0.0001 \\
\hline & $\mathrm{F}$ & 3289 & 1.47 & 0.99 & 0.69 & 0.0001 \\
\hline \multirow{2}{*}{ Work pace } & $\mathbf{M}$ & 6825 & 0.77 & 0.91 & 1.42 & 0.0001 \\
\hline & $\mathrm{F}$ & 3304 & 0.75 & 0.92 & 1.45 & 0.0001 \\
\hline \multirow[t]{2}{*}{ Conflicting demands } & $\mathbf{M}$ & 6829 & 0.66 & 0.95 & 1.59 & 0.0001 \\
\hline & $\mathbf{F}$ & 3315 & $0 \cdot 70$ & 0.94 & 1.53 & 0.0001 \\
\hline \multicolumn{7}{|l|}{ Objective: } \\
\hline \multirow{2}{*}{ Control } & $\mathbf{M}$ & 5879 & 1.09 & 0.99 & 0.93 & 0.2334 \\
\hline & $\mathbf{F}$ & 2858 & 0.97 & 1.01 & $1 \cdot 02$ & $0 \cdot 8862$ \\
\hline \multirow[t]{2}{*}{ Pace } & $\mathbf{M}$ & 5879 & 1.06 & 0.96 & 0.99 & 0.4262 \\
\hline & $\mathbf{F}$ & 2858 & 0.93 & 1.03 & 1.05 & 0.4557 \\
\hline \multirow[t]{2}{*}{ Conflicting demands } & $\mathbf{M}$ & 5879 & 0.97 & 1.01 & $1 \cdot 02$ & 0.7678 \\
\hline & $\mathbf{F}$ & 2858 & 0.90 & 1.09 & 1.02 & $0 \cdot 1916$ \\
\hline
\end{tabular}

Table 4 Mean anxiety and depression scores by work characteristics (tertiles) adjusting for age and employment grade

\begin{tabular}{|c|c|c|c|c|c|}
\hline \multirow[b]{2}{*}{ Work characteristics } & \multicolumn{3}{|l|}{ Scores } & \multirow[b]{2}{*}{$F$ value } & \multirow[b]{2}{*}{$p$ value } \\
\hline & 1 (low) & 2 (medium) & 3 (high) & & \\
\hline \multicolumn{6}{|l|}{ Men } \\
\hline $\begin{array}{l}\text { Anxiety: } \\
\text { Control } \\
\text { Work pace } \\
\text { Conflicting demands }\end{array}$ & $\begin{array}{l}4.69 \\
3.79 \\
3.60\end{array}$ & $\begin{array}{l}4 \cdot 27 \\
4 \cdot 18 \\
4 \cdot 19\end{array}$ & $\begin{array}{l}3 \cdot 97 \\
4 \cdot 82 \\
4 \cdot 98\end{array}$ & $\begin{array}{r}41 \cdot 7 \\
101.9 \\
167.9\end{array}$ & $\begin{array}{l}0.0001 \\
0.0001 \\
0.0001\end{array}$ \\
\hline $\begin{array}{l}\text { Depression: } \\
\text { Control } \\
\text { Work pace } \\
\text { Conflicting demands }\end{array}$ & $\begin{array}{l}1.85 \\
1.48 \\
1.23\end{array}$ & $\begin{array}{l}1.52 \\
1.54 \\
1.52\end{array}$ & $\begin{array}{l}1.33 \\
1.60 \\
1.83\end{array}$ & $\begin{array}{r}37 \cdot 5 \\
2 \cdot 3 \\
51 \cdot 1\end{array}$ & $\begin{array}{l}0.0001 \\
0.0977 \\
0.0001\end{array}$ \\
\hline $\begin{array}{l}\text { Women } \\
\text { Anxiety: }\end{array}$ & & & & & \\
\hline $\begin{array}{l}\text { Anxiety: } \\
\text { Control } \\
\text { Work pace } \\
\text { Conflicting demands }\end{array}$ & $\begin{array}{l}5 \cdot 11 \\
4 \cdot 25 \\
4 \cdot 07\end{array}$ & $\begin{array}{l}4 \cdot 65 \\
4 \cdot 69 \\
4 \cdot 63\end{array}$ & $\begin{array}{l}4 \cdot 45 \\
5 \cdot 08 \\
5 \cdot 44\end{array}$ & $\begin{array}{l}15 \cdot 7 \\
24 \cdot 8 \\
59 \cdot 0\end{array}$ & $\begin{array}{l}0.0001 \\
0.0001 \\
0.0001\end{array}$ \\
\hline $\begin{array}{l}\text { Depression: } \\
\text { Control } \\
\text { Work pace } \\
\text { Conflicting demands }\end{array}$ & $\begin{array}{l}1.78 \\
1.29 \\
1 \cdot 15\end{array}$ & $\begin{array}{l}1.34 \\
1.43 \\
1.33\end{array}$ & $\begin{array}{l}1.22 \\
1.52 \\
1.80\end{array}$ & $\begin{array}{r}21 \cdot 2 \\
3 \cdot 2 \\
22 \cdot 1\end{array}$ & $\begin{array}{l}0.0001 \\
0.0429 \\
0.0001\end{array}$ \\
\hline
\end{tabular}

acteristics was inserted in combination. As table 5 shows, each of the work characteristics had independent effects on the GHQ score when adjusting for the others. Moreover, there was no evidence of multiplicative interaction between psychological demands and control, as might have been predicted by the job strain model, but there was evidence of additive effects. There were no statistically significant interactions between work characteristics and sex in this model.

The association between work characteristics and psychiatric disorder could be explained by negative affectivity, a tendency to report negatively about both work characteristics and psychiatric disorder. This was tested using the affect balance scale. The GHQ screens for both mild and severe psychiatric disorder: it may also partly measure negative affectivity. The negative affect subscale of the affect balance scale measures milder dysphoria and may also measure negative affectivity. Thus, by examining the association between work characteristics and the GHQ score and adjusting for negative affect, one may also be adjusting for negative affectivity/plaintive set. For instance, control and work social support still show significant associations with the GHQ score after adjustment for negative affect (for men: control, $\mathrm{F}=5 \cdot 4$, df $2, \mathrm{p}<0.0045$; work social sup- port, $\mathrm{F}=14 \cdot 7$, df $2, \mathrm{p}<0.0001$; negative affect, $\mathrm{F}=1826.0$, df $1, \mathrm{p}<0.0001)$. However, in women after adjusting for negative affect, the effects of work social support and control became just non-significant (control, $\mathrm{F}=2 \cdot 88$, df $2, \mathrm{p}<0.0565$; work social support, $\mathrm{F}=2 \cdot 67$, df $2, \mathrm{p}<0.0695$, negative affect, $\mathrm{F}=1240 \cdot 2$, df 1 , $\mathrm{p}<0.0001)$. The difference in the mean GHQ score between the highest and lowest tertiles of work social support and control, adjusting for age, employment grade, and marital status, fell markedly after further adjusting for negative affect. In men, the difference fell from $1 \cdot 27$ to 0.57 for control and from 1.92 to 0.82 for support. In women the difference fell from $1 \cdot 12$ to 0.67 for control and from 1.71 to 0.53 for support.

\section{Discussion}

Positive characteristics of work (high levels of control, skill use and variety, work social support) in civil servants were found to be related to greater wellbeing and satisfaction and less psychiatric disorder. Conflicting demands were strongly associated with more psychiatric disorder but work pace showed a much weaker association and was not significantly associated with wellbeing. It has been suggested that work pace may have a non-linear association with wellbeing. Both extremes, too fast or too slow 
Table 5 Multiple regression analysis of the association between work characteristics and psychiatric disorder adjusting for age, marital status, and employment grade

\begin{tabular}{|c|c|c|c|c|c|}
\hline \multirow[b]{2}{*}{ Parameter } & \multicolumn{2}{|l|}{ Men } & \multicolumn{2}{|l|}{ Women } & \multirow[b]{2}{*}{$p$ (diff) } \\
\hline & Estimate & $p$ & Estimate & $p$ & \\
\hline Control & & 0.0001 & & $0 \cdot 0037$ & 0.6803 \\
\hline 0 & 0.942 & & 0.845 & & \\
\hline 1 & $0 \cdot 397$ & & $0 \cdot 142$ & & \\
\hline 2 & 0.000 & & 0.000 & & \\
\hline Variety, skill use & & 0.0001 & & 0.0002 & 0.8975 \\
\hline 0 & $1 \cdot 126$ & & $1 \cdot 254$ & & \\
\hline 1 & $0 \cdot 438$ & & 0.435 & & \\
\hline 2 & $0 \cdot 000$ & & 0.000 & & \\
\hline Work social support & & 0.0001 & & 0.0001 & $0 \cdot 3480$ \\
\hline 0 & $1 \cdot 554$ & & $1 \cdot 349$ & & \\
\hline 1 & $0 \cdot 717$ & & 0.305 & & \\
\hline 2 & 0.000 & & 0.000 & & \\
\hline Pace & & 0.0001 & & 0.0001 & 0.7231 \\
\hline 0 & $-1 \cdot 047$ & & $-1 \cdot 167$ & & \\
\hline 1 & $-1 \cdot 016$ & & -0.910 & & \\
\hline 2 & 0.000 & & 0.000 & & \\
\hline Conflicting demands & & 0.0001 & & 0.0001 & 0.6324 \\
\hline 0 & -1.867 & & $-2 \cdot 168$ & & \\
\hline 1 & $-1 \cdot 112$ & & $-1 \cdot 351$ & & \\
\hline 2 & $0 \cdot 000$ & & 0.000 & & \\
\hline No & 6774 & & 3226 & & \\
\hline
\end{tabular}

a pace, are undesirable and time pressure enhances self esteem..$^{25}$ Overall, interpretation of the statistical significance of results should be cautious because of multiple testing.

In men and women doing comparable jobs, the association between work and psychological health was similar. There was also no effect of adjusting for employment grade, presumably because there were minimal grade differences in the GHQ scores.

In comparing the association of positive work characteristics with the psychological indices it seems that skill and variety, followed by control and finally work social support, have the greatest associations with wellbeing and global satisfaction. In contrast, work social support has the greatest effect on psychiatric disorder followed by control and finally skill and variety. The importance of work social support in the association with psychiatric disorder is paralleled by the findings with personal social support in the non-work sphere. ${ }^{27}$

This study supports the differential relationship between psychological work demands, in terms of work pace, and anxiety and depression. However, dissecting psychological demands of work shows that conflicting job demands are powerfully related to both depression and anxiety. Moreover, unlike findings in the published reports, control is related to both anxiety and depression in this sample. It is interesting that these work dimensions have independent effects on psychiatric disorder. This supports the notion that these work characteristics can be separately defined and are not merely measuring a composite judgement of work dissatisfaction.

There is little overall support for a multiplicative interaction between job demands and decision latitude although an interaction was found for psychiatric disorder in men. Certainly the negative effects of high demands and low decision latitude seem additive, ${ }^{9}$ and combined they lead to the highest GHQ scores.

It is difficult to be certain of the direction of association in these cross sectional findings. Do poor work characteristics lead to less wellbeing and higher rates of psychiatric disorder? We will only be able to test this definitively with our longitudinal data. On the other hand, does psychiatric disorder lead to either reporting negatively about the work environment or a real deterioration in working conditions? ${ }^{3}$ The strong associations between subjective work characteristics and psychiatric disorder and wellbeing contrast with the weak associations between the objective work characteristics and psychiatric disorder. In combination with a relatively small association between objective and subjective work characteristics in this study, this would support a view that subjective work characteristics represent subjective perception alone and not the "real" characteristics of the working environment. However, the personnel manager's assessment of the characteristics of individual's work may not have been sufficiently accurate or comprehensive in this study, as they may not be sufficiently knowledgeable about the detail of individual workers' jobs. The extent to which personnel managers had direct or regular contact with employees varied between departments and between personnel managers within departments. In the published reports, there are moderate associations, although largely at the group level, between subjective perceptions of work and objective observer or supervisor perceptions of work. ${ }^{27}$ This suggests that subjective measures of work are at least partially measuring the same underlying constructs as the objective measures of work. Moreover, objective perceptions of work are strongly associated with mental health outcomes. This makes these other explanations less likely and supports the belief that subjective work characteristics are genuinely associated with psychological outcomes. Moreover, self report (as well as externally assessed) work characteristics have been related to short spells of sickness absence in this cohort suggesting that self reported work characteristics may predict illness related behaviour as well as self reports of illness. Subjective perception of work characteristics may be a mediating step between objective working conditions and psychological outcomes. This suggests that it may be the employees' perceptions and interpretation of their objective working conditions rather than the working conditions per se which directly 
influence wellbeing, satisfaction, and psychiatric disorder. ${ }^{28}$

It is likely, however, that the greater strength of association between subjective work characteristics and psychiatric disorder compared with the associations between objective work characteristics and psychiatric disorder suggest the association is partially explained by negative affectivity. Nevertheless, we still found associations between subjective work characteristics and psychiatric disorder, after attempting to adjust for the effects of negative affectivity, although the size of the effect was diminished. Negative affect on the affect balance scale is not a pure measure of negative affectivity. On one hand there may be overadjustment because negative affect is associated with the GHQ score thus reducing the association between work characteristics and the GHQ. On the other there may be underadjustment because negative affect is an incomplete index of negative affectivity. In a more formal testing of the effect of negative affectivity Chen and Spector ${ }^{29}$ measured negative affectivity and still found associations between work stressors and mental health outcomes after adjusting for negative affectivity.

It seems unlikely that psychiatric disorder will lead to deterioration in objective aspects of the work environment, although it is quite possible that psychiatric disorder might lead to a reduction in social support at work. This might partially explain the stronger association between work social support and psychiatric disorder than with the other "positive" characteristics of work. In addition, it seems unlikely that the relatively transient psychiatric disorder, which comprises most of the morbidity identified by the GHQ, would lead to selection into jobs with the worst job characteristics.

Overall, although reverse causation and negative affectivity may contribute to these associations, it seems likely that subjective perceptions of the work environment may affect wellbeing, satisfaction, and psychiatric disorder. If this is the case, it has substantial implications for improving levels of wellbeing and preventing psychiatric disorder in working populations. In the design of healthy workplaces it may not be enough to consider the objective conditions of work. It is necessary to take into account subjective perceptions of working conditions as well if levels of satisfaction, wellbeing, and psychiatric disorder are to be influenced. The possibility that both workplace design and management practices in turn may influence perceptions of control, social support, and conflicting demands in the workplace should be considered when intervention programmes are undertaken. This allows for intervention at the levels of design and work organisation to influence perceptions of work and thus also influence psychological health.

We thank all participating Civil Service departments and their welfare, personnel and establishment officers, and the Civil Service Central Monitoring Service, the Civil Service Occupational Health Service, Dr George Sorrie, Dr Adrian Semmence, the Council for Civil Service Unions, and all participating civil servants. Stephen Stansfeld thanks Dr John Frank and the Ontario Workers Compensation Institute for their support while writing this paper. Fiona North was supported by the Medical Research Council of New Zealand and National Heart Foundation of New Zealand.

We also thank Professor Geoffrey Rose and Mrs Ceridwen Rose, Professor Barry Lewis, Dr Brenda Slavin, Mr Edward Kearney and staff, Dr Peter Macfarlane, Dr John O'Brien, Dr Mike Etherington, Dr Tom Spuhler, and Ms Amanda Feeney, Ms Julie Moore (project coordinators).

This study was supported by the Medical Research Council, Health and Safety Executive, and National Heart Lung and Blood Institute (2 IO HAL36310-04).

1 Kasl SV. Mental health and work environment: an examination of the evidence. Fournal of Occupational Medicine 1973;15:509-18.

2 Karasek RA. Job demands, job decision latitude and mental strain: implications for job redesign. Administrative Science Quarterly 1979;24:285-306.

3 Frese $M$. Stress at work and psychosomatic complaints: a causal interpretation. $\mathcal{f}$ Appl Psychol 1985;70:314-28.

4 Payne R, Fletcher BC. Job demands, supports, and constraints as predictors of psychological strain among school-

teachers. fournal of Vocational Behaviour 1983;22:136-47. sonal income: their relation to psychological wellbeing in sonal income: their relation to psychological wellbe
men and women. $f$ Appl Psychol 1987;72:529-37.

6 Karasek R, Theorell T. Healthy work: stress, productivity and the reconstruction of working life. New York: Basic Books Inc, 1990.

7 Broadbent DE. The clinical impact of job design. $\mathrm{Br} \mathfrak{f}$ Clin Psychol 1985;24:33-44.

8 Hesketh B, Shouksmith G. Job and non-job activities, job satisfaction and mental health among veterinarians. fournal of Occupational Behaviour 1986;7:325-39.

9 Warr P. The measurement of wellbeing and other aspects of mental health. Fournal of Occupational Psychology 1990; 63:193-210.

10 Hackman JR, Oldham GR. Development of the Job Diagnostic Survey. F Appl Psychol 1975;60:159-70.

11 Johnson JV, Hall EM. Job strain, work place support and cardiovascular disease - a cross-sectional study of a random sample of the Swedish working population. $A m \mathcal{F}$ Public Health 1988;78:1336-42.

12 Johnson JV, Hall EM, Theorell T. Combined effects of job strain and social isolation on cardiovascular disease job strain and social isolation on cardiovascular disease morbidity and mortality in a random sample of Swedish male working popu
$1989 ; 15: 271-9$.

13 Aldag RJ, Barr SH, Brief AP. Measurement of perceived task characteristics. Psychol Bull 1981;90:415-31.

14 Spector PE. A consideration of the validity and meaning of self-report measures of job conditions. In: Cooper CL, Robertson IT, eds. International review of industrial and organizational psychology. New York: John Wiley and Sons, 1992;123-51.

15 Brief AP, Burke MJ, George JM, Robinson BS, Webster J. Should negative affectivity remain an unmeasured variable
in the study of job stress? $₹ \mathrm{Appl}$ Psychol 1988;73:193-8.

6 Kasl SV. Stress and disease in the work place: a methodological commentary on the accumulated evidence. In: odological commentary on the accumulated evidence. In: Cataldo MF, Coates TJ, eds. Health and industry: $a$ behavioral medicine perspective. New York: John Wiley and
Sons, 1984;52-85.

17 Marmot MG, Davey Smith G, Stansfeld S, et al. Health inequalities among British Civil Servants: the Whitehall inequalities among British Civil Serva

18 Goldberg DP. Detecting psychiatric illness by questionnaire. London: Oxford University Press, 1972. Maudsley Monograph 21

19 Goldberg DP, Blackwell B. Psychiatric illness in general practice. A detailed study using a new method of case identification. $B M \mathcal{F}$ 1970;ii:439-43.

20 Hanley JA, McNeil BJ. A method of comparing the areas under receiver operating characteristic curves derived from the same cases. Radiology 1983;148:839-43.

21 Stansfeld SA, Marmot MG. Social class and minor psychiatric disorder: a validated Screening Survey using the General Health Questionnaire in British Civil Servants. Psychol Med 1992;22:739-49.

22 Bradburn NM. The structure of psychological wellbeing. Chicago: Aldine, 1969.

23 Diener E, Emmons RA, Larsen RJ, Griffin S. The satisfaction with life scale. Fournal of Personality Assessment 1985;49:71-5.

24 North FM. Work and absence from work. London: University of London, 1990. PhD dissertation.

$25 \mathrm{Kohn}$ ML, Schooler C. Job conditions and personality: a longitudinal assessment of their reciprocal effect. American foumal of Sociology 1982;87:1257-86.

26 Kessler RC, McLeod JD. Social support and mental health in community samples. In: Cohen S, Syme SL, eds. Social support and health. London: Academic Press, 1985.

27 Spector PE, Dwyer DJ, Jex SM. Relation of job stressors to affective, health and performance outcomes: a comparison of multiple data sources. $\mathcal{F}$ Appl Psychol 1988;73: $11-19$.

28 Guendelman S, Silberg MG. The health consequences of maquiladora work: women on the US-Mexican border. Am $\mathcal{F}$ Public Health 1993;83:37-44.

29 Cohen PY, Spector PE. Negative affectivity as the underlying cause of correlations between stressors and strains. $\mathcal{F} A p p l$ Psychol 1991;76:398-407. 